\title{
Pertinence of Children's Chest X-Ray Request Form and Practice at the Regional Hospital of Ngaoundere Cameroon
}

\author{
Mathurin Guena Neossi ${ }^{1,2}$, Florent Zilbinkai Alapha² \\ ${ }^{1}$ Department of Biomedical Sciences, Faculty of Science, The University of Ngaoundere, Ngaoundere, Cameroon \\ ${ }^{2}$ Medical Imaging Center of Ngaoundere RegionalHospital, Ngaoundere, Cameroon \\ Email: mneossiguena@yahoo.fr
}

How to cite this paper: Neossi, M.G. and Alapha, F.Z. (2018) Pertinence of Children's Chest X-Ray Request Form and Practice at the Regional Hospital of Ngaoundere Cameroon. Open Journal of Radiology, 8, 223-235.

https://doi.org/10.4236/ojrad.2018.84026

Received: October 6, 2018

Accepted: November 5, 2018

Published: November 8, 2018

Copyright ( $) 2018$ by authors and Scientific Research Publishing Inc. This work is licensed under the Creative Commons Attribution International License (CC BY 4.0).

http://creativecommons.org/licenses/by/4.0/

\begin{abstract}
Background: Chest X-ray is frequently performed for evaluation of chest disease in both adults and children. Children are more exposed to the adverse effects of radiation as compared to adults. During our daily practice, we noticed that most of children's chest X-ray results were normal. Purpose: This study aimed to evaluate the indications, the technic, the irradiation and the result of chest X-rays in children in order to know if the practice of these $\mathrm{X}$-rays was relevant. Method: Cross-sectional and descriptive study conducted at the Imaging Regional Center of Ngaoundere from April to August 2017. A total number of 145 radiographs and $140 \mathrm{X}$-ray requests of 140 children were considered in this work. The conformity of the request were verified according to the recommendations of the National Agency for Accreditation and Health Evaluation in France (NAAHE), technical condition of realization and results were appreciated and the entrance surface dose (ESD) of the patients was estimated using a mathematical algorithm. Results: Children under 5 years $(63.5 \%)$ were more represented in our study. The main indications were: cough (22.1\%), suspicion of pneumonia (16.4\%) and bronchitis (15.7\%). No indication was mentioned on $69.3 \%$ of the request forms. After confrontation to the "Guide for proper use of medical imaging examinations" (GPU), we only had $24 \%$ conformity of indications. $82.7 \%$ of the examinations required immobilization assistance by the parents. Most of the children were imaged in a standing-up position (82.9\%) and the anterior-posterior view $(77.9 \%)$ was more practiced. After the analysis of the pictures, $62 \%$ of them presented an optimal contrast, while $42.1 \%$ of X-ray were performed without beam collimation. $25 \mathrm{X}$-rays were repeated: 12 (48\%) because of patient's motion and $13(52 \%)$ of mispositionning. After interpretation, 87 (62.14\%) chest X-ray were normal. Main lesion observed were pneumonia
\end{abstract}


(17.14\%) followed by bronchopeumopathy (5.71\%) and bronchitis (5\%). The obtained ESD values were $0.11,0.15$ and $0.17 \mathrm{mGy}$ respectively for the $0-1$ year, 1 - 5 year and 5 - 10 year age groups; 0.2 and 0.57 respectively for postero-anterior (PA) and lateral (LAT) view for the age group $10-15$ years, which were slightly greater than the values in internationally published studies. Conclusion: The request for children chest X-ray is not relevant in terms of indication, technical conditions of realization and irradiation.

\section{Keywords}

Pertinence, Chest X-Ray, Children, Request Form, Practice

\section{Introduction}

Chest radiography is the most frequently used examination in both adults and children in the world. Its large diffusion is related to the tuberculosis endemic period and its maintenance is due to the high frequency of respiratory infections and lung cancer [1]. Close attention should be paid to improve the diagnostic information as much as possible while it is important to keep radiation doses to the minimum when dealing with pediatric patients.

Frontal, antero-posterior (AP) or postero-anterior (PA) views and lateral view are requested during follow-up examinations and can be supplemented by particular incidences (lateral decubitus, hyperlordosis, expiration); these are always guided by the search for a specific pathology suspected by the clinic or detected on the initial images [2]. No act exposing to ionizing radiation can be practiced without an exchange of written information between the clinician and the radiologist [3]. But we found that the details provided by clinicians when requesting a chest X-ray are often insufficient. A recent study in Cameroon has shown that medical imaging exam request has many deficiencies in administrative and clinical details, and more importantly on X-ray requests [4].

Chest radiography is a frequently performed at a very low dose level. However, because of its frequency, it makes a notable contribution to the collective radiation risk of the population. In current practice, the technical implementation procedures do not provide an optimization of the radiation dose delivered to children, and children may be uncooperative and are frequently subject to a greater number of exposures than adult patients. In a study conducted at the Hospital and University Center (HUC) in Lomé, $61.76 \%$ of the chest X-rays performed in children was normal [5]. During our daily practice, we noticed that most of children's chest X-ray results were normal.

As part of a project to reduce the radiation dose and to improve the quality of the pediatric chest X-ray request forms, we conducted a survey to assess the pertinence of children's chest X-ray request form and practice at the Ngaoundere Medical Imaging Center, in the northern part of Cameroon. 


\section{Methods}

This study was carried out at the Regional Center for Medical Imaging of the Ngaoundere in the Northern part of Cameroon, between April and August 2017. It was a cross-sectional and descriptive study. Sampling was consecutive and exhaustive non-probabilistic. The study included all children aged from 0 to 15 years who came to the radiology and medical imaging department for chest $\mathrm{X}$-rays and freely consented to participate. All children's parents received the information and approved the study. Each patient recruited for this study had to go through a clinical examination including medical history, inspection and auscultation, followed by a chest X-ray. 140 requests for exams and 145 images were studied. The X-ray equipment used was a General Electric XR 6000 (May 2011), high-frequency three-phase model, with a $2.5 \mathrm{~mm}$ aluminium (AL) total beam filtration. The presence of the elements of conformity of the request according to the recommendations of the National Agency for Accreditation and Health Evaluation in France (NAAHE), (date of the request, service applicant, identification of the referring physician, identification of the patient, date of birth of the patient, anatomical region, indication for the examination) was verified and noted. For each examination, the patient's weight, height, age, lateral and frontal thicknesses were noted, together with the tube voltage $(\mathrm{kV})$, and focus-surface distance (FSD). The patient's complaints or the indication was also noted. The Indications recorded on the request forms were confronted to the French Society of Radiology recommendations. During the realization of the examination, the position of the children, the use or not of the means of restraint and the resumption of examinations or not were written down. In this study, 145 X-ray examinations (140 AP/PA views and 5 LAT view) of pediatric patients were acquired. Only the examinations that resulted in diagnostically acceptable radiographs were included in the study. After the film is obtained, it is interpreted by the radiologist. In the case of a control, comparison with prior films was done in evaluating the evolution of the observed lesion. The radiation dose to patients was calculated for chest X-rays according to the formula:

$$
\mathrm{ESD}=\mathrm{Y}(\mathrm{d}) \times\left(\frac{\mathrm{kVp}}{80}\right)^{2} \times \mathrm{mAs} \times\left(\frac{100}{\mathrm{FSD}}\right)^{2} \times \mathrm{BSF} \quad[6]
$$

$\mathrm{Y}$ (d) represents the tube output in $\mathrm{mGy} / \mathrm{mAs}$ calculated at $80 \mathrm{kVp}$, at a distance of $100 \mathrm{~cm}$ from the tube focus along the beam axis and $20 \mathrm{mAs}$ using a all in one universal calibrated X-ray exposure meter. The output for the X-ray tube was calculated by using equation below:

$$
\text { Output }=\frac{\text { Average dosimetre Readings }}{\text { tube current time product }(\mathrm{mAs})} \text { [7] }
$$

$\mathrm{kVp}$ is the peak tube voltage, $\mathrm{mAs}$ the exposure current-time product and FSD the focus-to-skin distance. Accordingly, the tube output of the X-ray machine was found to be $0.056 \mathrm{mGy} / \mathrm{mAs}$. BSF is the backscatter factor. A value for the BSF of 1.30 was used in this study [6]. The type of film use was Fuji "Blu" 
with a speed of 400 and a direct view cassette (computed radiograph system).

For analysis of the results, the patients were divided into the following age groups: 0 - 1 y, $1-5$ y, 5 - 10 y, and 10 - 15 y. Quantitative variables were expressed as mean and 75 th percentile.

Finally, the results of calculated ESD was compared with international recommended values of Diagnostic Reference Levels (DRL) and with similar studies conducted elsewhere. Microsoft Office Excel 2013 and Sphinx version 5.1.0.6 were used for data analysis. Chi-square test was used with a precision threshold $\mathrm{p}=0.05$.

\section{Results}

The study included 140 patients aged 7 days to 15 years. Children under 5 years $(63.5 \%)$ were more represented in this study (Table 1$)$. The male sex was the most represented.

The main indication was cough (22.1\%), followed by chest pain and dyspnea. There is no indication in $69.3 \%$ (Table 2). The Indications recorded on the request forms were confronted to the "Guide for proper use of medical imaging examinations" (GPU) of the French Society of Radiology (FSR) (Figure 1). We only had $24 \%$ conformity of indications.

According to Table 3, 62.14\% of chest X-ray was normal. Main lesion observed were pneumonia (17.14\%) followed by broncho-penumopathy $(5.71 \%)$ and bronchitis $(5 \%)$.

\subsection{Technical Realization}

82.9\% of the children were imaged in a standing-up position (Figure 2) and the anterior-posterior view (71.7\%) was more practiced (Figure 3).

It appears in Table 4 that no restraint was used during examination, $42.1 \%$ of $\mathrm{X}$-rays were performed without X-ray beam collimation. $62.1 \%$ of X-rays were performed in the presence of parents. $82.7 \%$ of the examinations required immobilization assistance by the parents, none of them was wearing leaded apron.

As shown in Table 5, 62\% of the images had an adequate density. Despite the fact that 55 (38\%) images had inadequate density this did not prevent their exploitation. $25 \mathrm{X}$-rays were repeated due to motion (48\%) and mispositioning $(52 \%)$.

Table 1. Distribution of patient by age group.

\begin{tabular}{ccc}
\hline Age group & Frequency & Percentage (\%) \\
\hline $0-1$ y & 45 & 32.1 \\
$1-5 y$ & 44 & 31.4 \\
$5-10 y$ & 27 & 19.3 \\
$10-15 y$ & 24 & 17.2 \\
Total & 140 & 100
\end{tabular}


Table 2. Distribution of indications.

\begin{tabular}{ccc}
\hline Patient's complaints & Frequency & Percentage (\%) \\
\hline None & 97 & 69.3 \\
Cough & 31 & 22.1 \\
Chest pain & 6 & 4.3 \\
Dyspnea & 4 & 2.9 \\
inhalation of foreign body & 2 & 1.4 \\
Total & 140 & 100 \\
\hline
\end{tabular}

Table 3. Chest X-ray results.

\begin{tabular}{ccc}
\hline Results & Frequency & Percentage (\%) \\
\hline Normal chest incidence & 87 & 62.14 \\
Pneumopathy & 24 & 17.14 \\
Broncho-pneumopathy & 8 & 5.71 \\
Bronchitis & 7 & 5 \\
Pleurisy & 5 & 3.5 \\
Pneumothorax & 4 & 2.8 \\
Bronchiolitis & 2 & 1.4 \\
Foreign body inside respiratory tract & 2 & 1.4 \\
Pulmonary tuberculosis & 1 & 0.7 \\
Total & 140 & 100 \\
\hline
\end{tabular}

Table 4. Data relative to the observation of chest X-ray realization.

\begin{tabular}{|c|c|c|}
\hline Observation & Frequency & Percentage (\%) \\
\hline Use of restraints & & \\
\hline - Yes & 0 & 0 \\
\hline - No & 140 & 100 \\
\hline $\mathrm{X}$ ray beam collimation & & \\
\hline - Yes & 81 & 57.8 \\
\hline - No & 59 & 42.1 \\
\hline Parental presence in examination room & & \\
\hline - Yes & 87 & 62.1 \\
\hline - No & 53 & 37.3 \\
\hline Parental support for child immobilization & & \\
\hline - Yes & 72 & 82.7 \\
\hline - No & 15 & 17.2 \\
\hline Parental wearing of lead apron & & \\
\hline - Yes & 0 & 0 \\
\hline - No & 87 & 100 \\
\hline
\end{tabular}


Conform Non conform Without indication

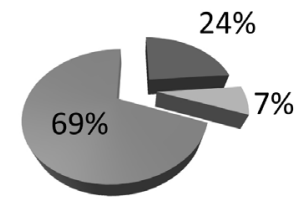

Figure 1. Conformity of indications to GPU.

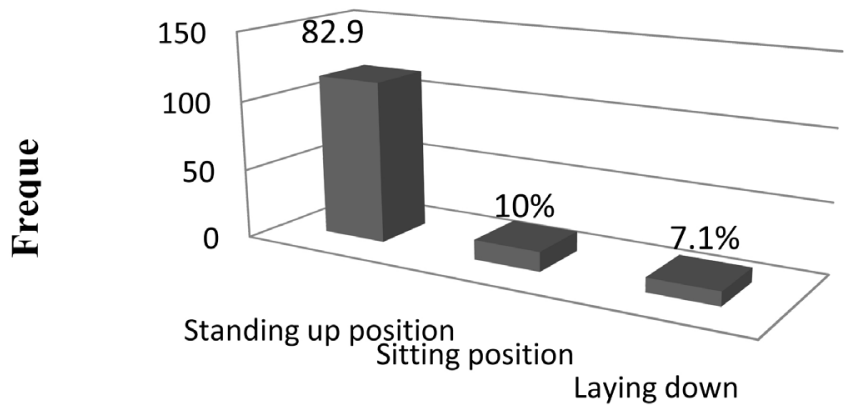

Figure 2. Child position during examination.

$21.3 \%$

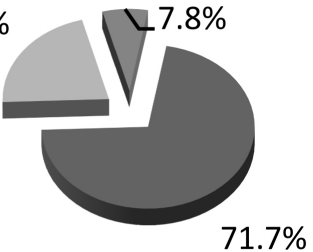

Anterio-posterior view

Postero-anterior view

Figure 3. Incidence achieved.

Table 5. Image quality.

\begin{tabular}{ccc}
\hline Image quality & Frequency & Percentage (\%) \\
X-ray penetration & \multicolumn{2}{c}{145} \\
- Too low density & 10 & 7 \\
- Adequate density & 90 & 62 \\
- Too high density & 45 & 31 \\
Repeating examination & & 25 \\
- Motion blur & 12 & 48 \\
- Mispositioning & 13 & 52 \\
\hline
\end{tabular}

15 patients were referred for a control X-ray (Table 6): 5 patients after 3 days of treatment, 4 patients after 4 days and 6 after one week of treatment. Regression of the lesions was observed on 1 image taken at a delay of seven days after taking the initial image.

\subsection{Technical Parameters}

It was seen according to Table 7 that the mean $\mathrm{kVp}$ and $\mathrm{mAs}$ increases with patient age. 
Table 6. Comparison to prior image.

\begin{tabular}{ccccc}
\hline \multicolumn{2}{c}{ Evolution of the observed lesion } & \multicolumn{2}{c}{ Total } \\
\hline Control delay & Regression & Stability & Frequency & Percentage (\%) \\
\hline Three days & 0 & 5 & 5 & 33.3 \\
Four days & 0 & 4 & 4 & 26.6 \\
Seven days & 1 & 5 & 6 & 40 \\
Total & 1 & 14 & 15 & 100 \\
\hline
\end{tabular}

Table 7. Patient exposure parameters per age and weight.

\begin{tabular}{|c|c|c|c|c|c|c|c|c|c|c|c|}
\hline \multirow{2}{*}{ Chest X-ray } & \multirow{2}{*}{$\begin{array}{l}\text { Age } \\
\text { group }\end{array}$} & \multirow{2}{*}{$\begin{array}{c}\text { Weight } \\
(\mathrm{Kg})\end{array}$} & \multicolumn{3}{|c|}{$\mathrm{kVp}$} & \multicolumn{3}{|c|}{$\mathrm{mAs}$} & \multicolumn{3}{|c|}{$\mathrm{FSD}(\mathrm{cm})$} \\
\hline & & & Min & Mean & Max & Min & Mean & Max & Min & Mean & Max \\
\hline \multirow{4}{*}{$\mathrm{AP} / \mathrm{PA}$ view } & $0-1 y$ & $3-14$ & 70 & 91 & 100 & 1 & 1.7 & 2 & 100 & 124 & 137 \\
\hline & $1-5 y$ & $7-20$ & 90 & 95 & 110 & 1.6 & 1.9 & 2.5 & 115 & 128 & 139 \\
\hline & $5-10 y$ & $10-25$ & 95 & 106 & 120 & 2 & 2.1 & 2.5 & 126 & 134 & 139 \\
\hline & $10-15 y$ & $20-55$ & 110 & 119 & 125 & 2 & 2.4 & 3 & 133 & 142 & 150 \\
\hline LAT view & $10-15 y$ & $32-46$ & 125 & 126 & 128 & 6 & 6.1 & 8 & 139 & 143 & 150 \\
\hline
\end{tabular}

Table 8 shows the descriptive statistics of ESD (mGy) values obtained in this study. The highest mean ESD was seen in lateral chest X-ray view ( $0.53 \mathrm{mGy})$. The lowest mean ESD was observed in the age group, 1 week - 1 year with 0.09 mGy.

This study shows that the third quartile ESD recorded in this work are higher for all age groups than the values in internationally published studies (see Table 9).

\section{Discussion}

The most represented age group was 0 to 1 year (32.1\%). This rate is similar to the 32\% found by Agbéré A et al., [13]. This outlined the fact that newborns and infants may be more exposed to respiratory disease. There is a male predominance with a sex ratio of 1.18 and is comparable to those of Agbéré A et al. (1.15) in Lomé And Sawadogo A. et al. (1.20) in Ouagadougou [13] [14]. Cough (22.1\%) was the main indication for chest X-ray. These results are close to those found by LK Agoda Koussema et al., although with a slightly higher rate of $28.43 \%$ [5]. Coughing is a normal defensive process which allows the clearance of excess mucus or aspirated material and is a common complaint of parents and a source of worry. It is an extremely common functional sign that can be found in most respiratory disease and is the third reason for consultation in general practice [15].

\subsection{Clinical Information}

As results, $62.14 \%$ of radiographs were normal against $37.86 \%$ pathological. Pneumopathy (17.14\%) was the main lesion observed. LK Agoda Koussema et al., 
Table 8. Presentation of dose values at the entrance ( $m G y$ ) according to the weight of the patient.

\begin{tabular}{ccccccc}
\hline \multirow{2}{*}{ Chest X-ray } & Age & \multicolumn{5}{c}{ ESD (mGy) } \\
\cline { 3 - 7 } & & Min & Max & Mean & $3^{\text {rd }}$ Quartile & Sd \\
\hline \multirow{2}{*}{ AP/PA view } & 1 week - 1 y & 0.05 & 0.15 & 0.09 & 0.11 & 0.02 \\
& $5-10 y$ & 0.11 & 0.2 & 0.15 & 0.17 & 0.03 \\
& $10-15 y$ & 0.11 & 0.23 & 0.18 & 0.2 & 0.03 \\
LAT view & $10-15 y$ & 0.42 & 0.57 & 0.53 & 0.57 & 0.1 \\
\hline
\end{tabular}

Table 9. Comparison of the third quartile ESD value of this study with Literature Data.

\begin{tabular}{cccccccc}
\hline Chest X-ray & Age group & $\begin{array}{c}\text { This study } \\
(2007)\end{array}$ & $\begin{array}{c}\text { Saudi Arabia } \\
(2015)[8]\end{array}$ & $\begin{array}{c}\text { Austria } \\
(2010) \\
{[9]}\end{array}$ & $\begin{array}{c}\text { France } \\
(2009) \\
{[10]}\end{array}$ & $\begin{array}{c}\text { Brazil } \\
(2009) \\
{[11]}\end{array}$ & $\begin{array}{c}\text { Finland } \\
(2007) \\
{[12]}\end{array}$ \\
\hline & $0-1 \mathrm{y}$ & 0.11 & 0.08 & 0.05 & 0.12 & 0.1 & 0.04 \\
& $1-5 \mathrm{y}$ & 0.15 & 0.11 & 0.06 & 0.10 & 0.07 & 0.07 \\
AP/PA view & $5-10 \mathrm{y}$ & 0.17 & 0.07 & 0.08 & 0.2 & 0.08 & 0.06 \\
& $10-15 \mathrm{y}$ & 0.2 & 0.11 & 0.08 & $/$ & 0.09 & 0.08 \\
\hline \multirow{2}{*}{ LAT view } & $10-15 \mathrm{y}$ & 0.57 & $/$ & $/$ & $/$ & $/$ & 0.31 \\
\hline
\end{tabular}

has found $61.76 \%$ normal X-rays and $38.24 \%$ pathological and with $53.85 \%$ of pneumopathy [5]. Indeed in our tropical context, the dominant pathology is essentially infectious. Low respiratory infections, especially pneumonia, are the leading causes of morbidity and mortality among young children in developing countries [16]. This considerable rate of normal X-rays (62.14\%) only highlights the fact that a large number of prescribed X-rays are not justified even though it is known that a justified medical imaging examination can sometimes be sanctioned by a normal report.

During our study, 15 control chest X-rays showed regression of lesions on 1 image taken at 7 days after the initial image. In practice, it is unnecessary and useless to ask for a control chest X-ray for a child with pneumonia. Only the clinical evolution must be followed. The persistence of symptoms can lead to request a control chest X-ray. In this study, the delay between initial and control chest X-ray was short, in order to guarantee a radiological evolution, the delay must be at least 10 days for bacterial pneumonia and 21 days for viral or atypical pneumonia [17]. Chest X-ray is often unable to detect early changes of pneumonia [18].

\subsection{Request Form}

On $30.7 \%$ of the requests form, the clinical information provided was a symptom. This result is similar to that found by Moifo et al. (30.9\%) in 2013 [19]. The pertinence of the request form requires a good formulation of the examination's 
purpose, the synthesis of the clinical history leading to this request, but also of the context and the history justifying a particular care, including the management of the risks related to the act requested [20]. There was no indication in $69.3 \%$ of the request forms. This is higher than those found by Moifo et al. (17.2\%) and by Roussel and Lelievre (20\%) [19] [21]. The indication is not only an element of justification for the imaging procedure, but is also an essential parameter for technical choices and in the interpretation of the images, some referring physicians are not aware on its importance. Moifo et al. in 2014 showed that the knowledge of physicians on radiating medical procedures and justification of requests were inadequate [22]. The presence of clinical information improves the interpretation of images, and in their absence, errors in the perception of radiological abnormalities can be as high as 60\% [23]. After confrontation of indication to the "Guide for proper use of medical imaging examinations" (GPU) of the French Society of Radiology (FSR), requested examination was conform only in $24 \%$.

\subsection{Technical Conditions}

The chest $\mathrm{x}$ ray technique in children differs from one patient to another according to their age and cooperation. In young children, the patient lies on the table and the hands are held above the head. In an older patient, the child stands upright and then in a lateral view as the images is obtained. In this study, most of the children were imaged in a standing-up position $(82.9 \%)$ and the anterior-posterior view (77.9\%) was more practiced. According to Brunelle, only the frontal view in deep inspiration, while standing is the only initial image to ask to diagnose pneumonia, systematic lateral view is useless in the majority of cases (98\%) except when there is a doubt [24]. Sometimes children are frightened by the large and unfamiliar equipment in the X-ray room. Antero-posterior view was most often preferred because it was reassuring for most children and the thymus is well seen in infants up to 2 years.

$87(62.1 \%)$ of parents or guides were present in the examination room, 72 (82.7\%) of them helped to immobilize children because they don't cooperate or their bad general state of health. None of the parent was wearing lead apron. Parents were allowed to be with the child to aid the study and for reassurance of the child. When the image is about to be taken, parents are encouraged to remind the child to hold still so that the picture will be sharp and clear. But parents should be provided a lead apron anytime they are in the $\mathrm{x}$-ray room with their child. This is consistent with the concept of keeping radiation dose as low as reasonably achievable (ALARA) [25].

A total of 25 chest X-ray was repeated including 12 (48\%) due to motion blur and $13(52 \%)$ due to the mispositionning of the child. Restraining the child is necessary, as it is in the best interest of the patient to have an adequate exposition. In some subsaharian countries like Cameroon, there is a lack of suitable equipment for restraining children in radiology unit, so the technologist have to 
work in tandem with parents to optimize techniques in working with the child in order to reduce radiation exposure by not repeating the examination. Schmit $\mathrm{P}$ found that $13 \%$ of parents were present in the X-ray examination room [26]. In developed countries, there are policies for X-ray facility and radiology units are equipped with dedicated devices to children and restraining equipment.

\subsection{Image Quality}

A total of 90 (62\%) of images had an adequate density while $31 \%$ were overexposed but were selected. LK Agoda Koussema et al. found $80.49 \%$ good images quality, $3.25 \%$ overexposed, $2.43 \%$ underexposed and $14.02 \%$ were rejected [5]. Fujifilm computed radiograph system with direct view cassette was used in our study. Computed radiograph has a good spatial and contrast resolution comparable to those of screen-film radiography [2]. In Fujifilm computed radiography (FCR) devices, there is software called Multi-frequency Processing (MFP) which provides more diagnostic data from a single exposure image. MFP improves visibility of both dense (mediastinum) and peripheral tissue (pulmonary parenchyma). The radiation X-ray beam was not cone in 59 (42.1\%) patient (Figure 4). This increases the scatter radiation to other parts of the body. Soboleski et al. in 2006 concluded present positioning techniques in neonatal and pediatric chest radiography result in unnecessary radiation exposure to non-thoracic structures, like the thyroid and the gonads, because they do not bring any clinical interest [27]. Emphasis should be placed on technologist to tightly cone the radiation beam to limit the area to be irradiated.

\subsection{Radiation Exposure}

Radiation protection in pediatric radiology requires a more special attention than in adult radiology because children have a longer life expectancy than

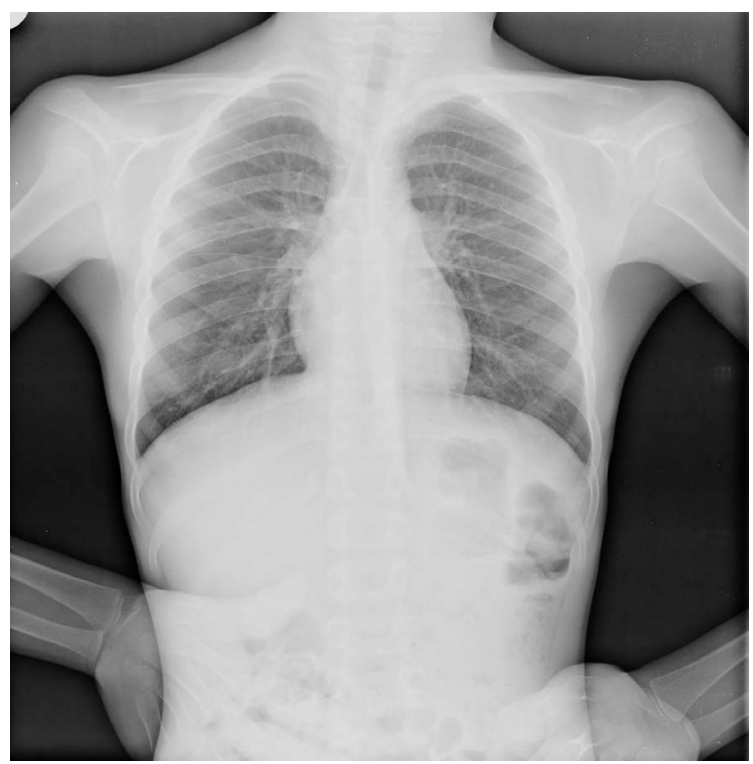

Figure 4. Insufficient X-ray beam closure. 
adults and are therefore at a greater risk to the long-term side effects of radiation. It can be seen in Table 7 that the exposure parameters used for different $\mathrm{X}$-ray examinations varied with the age group. The tube voltage values used in this study are higher than those recommended by the European Commission and those of Zewdu et al. in Ethiopia [7] [28]. The obtained ESD values were mostly higher than the values in internationally published studies [8] [9] [10] [11] [12]. This can be explained by the use of short focus to skin distance and by the fact that technologist are focused to ensure a good quality of image instead of parameters adjustment. The use of optimum FSD is considered very important since a direct relationship between shorter FSD, higher patient's dose and decreased geometric sharpness has been well established. The International Commission on Radiological Protection (ICRP) recommends the use of Diagnostic Reference Levels (DRL) as a first measure of radiation dose optimization for patients [29]. There is not yet in Cameroon DRL in pediatric imaging. This study shows the need to establish pediatric Local Diagnostic Reference Levels (LDRLs) and can be used as a baseline upon which future dose measurements may be compared.

As limitations: this study concerns a single hospital and can not give a real idea of the practice of the chest x-ray in the child in our country, but nevertheless it gives as well guidance on the practice of this exam and can allow to take decisions.

\section{Conclusion}

The request form for children chest X-ray is not relevant. The dosimetric evaluation allowed us to observe dose variations for the same age and weight class. The dose values obtained were higher than those presented by some recent publications. All this could be explained by the non-compliance of equipment that is not specific to pediatric radiology, a lack of standardization of examination protocols and also a lack of training of personnel in pediatric radiology. The results of the present study indicate a need to improve the quality of examination request form and to establish pediatric Local Diagnostic Reference Levels (LDRLs).

\section{Conflicts of Interest}

The authors declare that there is no conflict of interests regarding the publication of this paper.

\section{References}

[1] Hanquinet, S., Ferey, S. abs Kalifa, G. (2009) Practical Pediatric Imaging. Elsevier Masson, Paris. (Medical Imaging-Practice) https://archive-ouverte.unige.ch/unige:33241

[2] Chateil, J.-F., Durand, C. and Diard, F. (2005) Normal X-Ray of Face and Chest Profile in Children. EMC-Radiology, 587-616.

[3] Decree No. 2003-270 of 24 March 2003 on the Protection of Persons Exposed to Ionizing Radiation for Medical and Forensic Purposes and Amending the Public 
Health Code.

https://www.legifrance.gouv.fr/eli/decret/2003/3/24/SANP0320872D/jo/texte

[4] NdehKamgnie, M. (2012) Conformity Assessment of Requests for Medical Imaging Examinations at the Gyneco-Obstetrics and Pediatric Hospital of Yaounde (HGOPY). End of Study Thesis Specializing in Medicine, Option Radiology and Imaging. FMSB, University of Yaounde I.

[5] AgodaKoussema, L.K., N'dakena, K. and Adjenou, K.V. (2006) Standard Chest Radiography in the Practice of Radiopediatrics. About 102 Cases Collected at Lomé University Hospital. African Journal of Medical Imaging, 2, 102-109.

[6] Olowookere, C.J., et al. (2009) Comparison of Five Models for Assessing Patient Dose From Radiological Examinations. African Journal of Medical Physics, Biomedical Engineering \& Sciences, 1, 21-29.

[7] Zewdu, M., Kadir, E. and Berhane, M. (2017) Assessment of Pediatrics Radiation Dose from Routine X-Ray Examination at Jimma University Hospital, Southwest Ethiopia. Ethiopian Journal of Health Sciences, 27, 481-490. https://doi.org/10.4314/ejhs.v27i5.6

[8] Suleiman, A. (2015) Current Status of Radiation Dose Levels in Conventional Pediatric Radiography: A Review Study. Open Journal of Radiology, 5, 104-110. https://doi.org/10.4236/ojrad.2015.52016

[9] Billinger, J., Nowotny, R. and Homolka, P. (2010) Diagnostic Reference Levels in Pediatric Radiology in Austria. European Radiology, 20, 1572-1579.

https://doi.org/10.1007/s00330-009-1697-7

[10] Institute of Radioprotection and Nuclear Safety (IRNS). PRP-HOM Report/2012-12 Analysis of Data Relating to the Update of Diagnostic Reference Levels in Radiology and Nuclear Medicine-2009-2010 Report.

https://www.sfmn.org/images/pdf/GroupesDeTravail/GT_Radioprotection/IRSN_N RD_rapport_2009_2010.pdf

[11] Mohamadain, K.E.M. and Azevedo, A.C.P. (2009) Radiation Dose Survey in Conventional Pediatric Radiology. Journal of Science and Technology (Sudan), 10, No. 2.

[12] Kiljunen, T., et al. (2007) Diagnostic Reference Levels for Thorax X-Ray Examinations of Paediatrics Patients. The British Journal of Radiology, 80, 452-459.

[13] Agbéré, A., Tatagan, K., Kpémissi, E., Atakouma, D.Y., Kessié, K. and Assimadi, K. (1994) Place of Acute Respiratory Infections in Pediatric Pathology at CHR Kara-Togo. Health News, No. 30, 15-21.

[14] Sawadogo, A., Koueto, F., Sanou, I., Kam, K. and Dao, L. (1999) Infantile Pleuropulmonary Staphylococcal Disease in Hospital in Ouagadougou (Burkina Faso). Health Papers, 9, 209-213.

[15] Irwin, R.S. and Widdicombe, J.S. (1995) Cough. In: Murray, J.J. and Nadel, J.A., Eds., Textbook of Respiratory Medicine, WB Saunders, Philadelphia, 529-544.

[16] UNICEF (2008) State of the World's Children. https://www.unicef.org/french/publications/index_42625.html

[17] Marguet, C. (2010) Childhood Pneumonitis, Interactive Development, Pediatric Realities No. 150 May 2010.

http://www.sfmu.org/upload/70_formation/02_eformation/02_congres/Urgences/u rgences2015/donnees/pdf/018.pdf

[18] Hazir, T., Nisar, Y.B., Qazi, S.A., Khan, S.F., Raza, M., Zameer, S. and Masood, S.A. (2006) Chest Radiography in Children Aged 2-59 Months Diagnosed with Non-Severe Pneumonia as Defined by World Health Organization: Descriptive 
Multicentre Study in Pakistan. BMJ: British Medical Journal, 333, 629. https://doi.org/10.1136/bmj.38915.673322.80

[19] Moifo, B., NdehKamgnie, M., NinyingFuh, F., Zeh, O.F., Tebere, H., Moulion Tapouh, J.R., Edzimbi, A.L. and Nko'o-Amvene, S. (2013) Pertinence of Medical Imaging Exam Indications to Yaoundé-Cameroon. Health Sciences and Diseases, 14. http://www.hsd-fmsb.org

[20] Bruel, J.M., Valette, P.J. and Rahmouni, A. (2009) Demand for Imaging: A Key Factor in Improving the Quality of Patient Management. Journal of Radiology, 90, 1486-1487. https://doi.org/10.1016/S0221-0363(09)75815-9

[21] Roussel, N. and Lelièvre, P. (2002) Improve the Quality of Medical Imaging Exam Prescriptions. Journal of Radiology, 83, 621-625.

[22] Moifo, B., et al. (2014) Referring Physicians' Knowledge on Justification of Medical Exposure in Diagnostic Imaging in a Sub-Saharan African Country, Cameroon. Open Journal of Radiology, 4, 60-68. https://doi.org/10.4236/ojrad.2014.41008

[23] Aideyan, U.O., Berbaum, K. and Smith, W.L. (1995) Influence of Prior Radiologic Information on the Interpretation of Radiographic Examinations. Academic Radiology, 2, 205-208. https://doi.org/10.1016/S1076-6332(05)80165-5

[24] Brunelle, F. (1998) Radiological Approach to Community-Acquired Pneumonia. Archives de Pédiatrie, 5, s26-s27. https://doi.org/10.1016/S0929-693X(97)83485-9

[25] AEA (2001) Radiological Protection for Medical Exposure to Ionizing Radiation. Safety Standards Series rs-g-1.5, IAEA, Vienna.

[26] Schmit, P., Kalifa, G. and Devred, P. (1996) Parental Presence in Pediatric Imaging. Journal of Radiology (Paris), 77, 60-63.

[27] Soboleski, D., Theriault, C., Acker, A., Dagnone, V. and Manson, D. (2006) Unnecessary Irradiation to Non-Thoracic Structures during Pediatric Chest Radiography. Pediatric Radiology, 36, 22-25. https://doi.org/10.1007/s00247-005-0016-y

[28] European Commission (1996) European Guidelines on Quality Criteria for Diagnostic Radiographic Images in Paediatrics. EUR, Luxembourg.

[29] International Commission of Radiological Protection (1991) 1990 Recommendations of the International Commission of Radiological Protection. ICRP 60. Pergamon Press, Oxford. 